\title{
DEVELOPMENT OF POLY (LACTIC-CO-GLYCOLIC ACID)/ BIOGLASS FIBERS USING AN ELECTROSPINNING TECHNIQUE
}

\author{
N. BRIZUELA GUERRA ${ }^{\dagger}$, D. CORREA FERRÁN ${ }^{\ddagger}$, V. CALDAS DE SOUSA ${ }^{\dagger}$, \\ J.A DELGADO GARCÍA-MENOCAL ${ }^{\ddagger}$, M. GARCÍA VALLÉS ${ }^{\S}$, S. MARTÍNEZ , \\ L. MOREJÓN ALONSO* ${ }^{*}$ and L.A. LOUREIRO DOS SANTOS ${ }^{\dagger}$ \\ $\uparrow$ LaBiomat, Federal University of Rio Grande do Sul, 91501-970, Porto Alegre, Brazil. nayrimb@gmail.com \\ + Biomaterials Center, Universidad of Havana, 10400, Havana, Cuba. \\ $\S$ Faculty of Earth Sciences, University of Barcelona, 08028, Spain.
}

\begin{abstract}
This work establishes experimental conditions for the synthesis of polymeric fibers using the electrospinning technique, modifying some operational parameters such as drum collector rotation speed and applied voltage were modified. The samples were obtained from a copolymer of poly(lacticco-glycolic acid) (PLGA), with a molecular weight of approximately $220,000 \mathrm{~g} / \mathrm{mol}$, dissolved in a dimethyl sulfoxide/dichloromethane $(3: 1 \mathrm{v} / \mathrm{v})$ solution. With the aim of developing scaffolds for bone tissue engineering, we added a calcium phosphate glass based on 44.5CaO-44.5 $\mathrm{P}_{2} \mathrm{O}_{5}-11 \mathrm{Na}_{2} \mathrm{O}$ to the fibrous PLGA structures. The preliminary characterization of these PLGA structures with and without the addition of biodegradable glass was performed using SEM analysis. We found the formation of aligned and homogeneous fibers with an average diameter of $5.2 \pm 2.1$ $\mu \mathrm{m}$ when using the $800 \mathrm{rpm}-8 \mathrm{~cm}-9 \mathrm{kV}$ parameters. In addition, the incorporation of $1 \mathrm{wt.} \%$ of previously silanized calcium phosphate particles substantially altered the fiber morphology and porosity. However, a substantial increase in the bioactivity of the composite was observed in contrast with the unmodified PLGA.
\end{abstract}

Keywords - Electrospinning, calcium phosphate glass, PLGA, microfibers

\section{INTRODUCTION}

Diverse technologies have been developed to fabricate three-dimensional (3D) porous scaffolds (O'Brien, 2014), and of these, electrospinning has proven to be a simple and versatile technology for producing ultrathin non-woven fibers with a diameter ranging from nanometers to microns (Bhardwaj and Kundu, 2010). The electrospun nanofibers possess numerous advantages, such as an extremely high surface-to-volume ratio, a small inter-fibrous pore size with tunable porosity, and a vast range of possibilities for achieving desirable properties and functionalities. They have therefore been widely used in the areas of filtration, composite reinforcement, drug delivery and tissue engineering (Haghi and Akbari, 2007). A variety of materials including polymers, ceramics and their composites can be electrospun into fibrous scaffolds.

The principle of electrospinning was first studied by Formhals in the 1930s, and again attracted considerable attention in the 1990s (Formhals, 1934). A typical elec- trospinning setup is composed of three basic elements: a high voltage power supply, a capillary (including a solution container and a spinneret) and a grounded metal collector (usually aluminum foil) (Reneker and Yarin, 2008).

Electrospinning, a spinning technique, is a unique approach that uses electrostatic forces to produce fine fibers from polymeric solutions or melts. The fibers produced in this way have thinner diameters and larger surface areas than those obtained from conventional spinning processes. Furthermore, a voltage in the range of several tens of $\mathrm{kVs}$ is necessary for electrospinning (Lannutti et al., 2007).

There are a variety of parameters that influence the morphology and diameter of the electrospun fibers, including the intrinsic properties of the solution (e.g., the type of polymer, viscosity/concentration, elasticity, electrical conductivity, and the polarity and surface tension of the solvent), the operational conditions (e.g., the strength of the applied electric field, the distance between the spinneret and the collector, and the feeding rate for the polymer solution) and the humidity and temperature of the surroundings (Long et al., 2011).

In the electrospinning process, a polymeric solution held by its surface tension at the end of a capillary tube is subjected to an electric field, and an electric charge is induced at the liquid surface due to the presence of the electric field. When the applied electric field reaches a critical value, the repulsive electrical forces overcome the surface tension forces. Eventually, a charged jet of solution is ejected from the tip of the Taylor cone, and an unstable and a rapid whipping of the jet occurs in the space between the capillary tip and collector, leading to evaporation of the solvent and leaving behind a polymer. Some of the advantages of electrospinning are easy manipulation, cost-effectiveness and the possibility of producing nano and and microfibers with a wide range of compositions and morphologies (Liang et al., 2007).

A wide range of polymers used in electrospinning are able to form fine nanofibers, within the submicron range necessary for biomedical applications. Electrospun nanofibers have been reported from various synthetic polymers, natural polymers or a blend of both, including proteins. To date, electrospinning has been used for the fabrication of nanofibrous scaffolds from numerous biodegradable polymers, such as poly $(\varepsilon-$ caprolactone) (PCL), poly (lactic acid) (PLA), poly 
(glycolic acid (PGA) and copolymer poly(lactic-coglycolic acid) (PLGA), for applications such as bone tissue engineering, cardiac grafts, wound dressings and the engineering of blood vessel substitutes (Zander, 2013). PLGA is the most popular choice for biomaterial applications of biodegradable polymers; it has shown immense potential as a drug delivery carrier and in scaffolds for tissue engineering (Ngiam et al., 2009).

The incorporation of a bioceramic into a nanofibrous polymer matrix can take advantage of the mechanical properties, degradation stability and cell affinities of the individual components, generating a better biological response from the scaffold. The reason for this is that it mimics both the physical architecture and chemical composition of natural bone extracellular matrix, since it has a highly complex and well-harmonized composite structure consisting of type I collagen fibrils mineralized with a thin, highly crystalline carbonated hydroxyapatite layer (Lin et al., 2012).

Of the possible inorganic components, calcium phosphate glasses are currently being studied, as these can be prepared with a chemical composition analogous to natural bone, their solubility can be tailored to specific applications and several biocompatibility studies have demonstrated that these glasses do not produce adverse cell reactions in osteoblasts or fibroblasts. In addition, some reports reveal that calcium phosphate glasses can support the attachment, growth, and differentiation of human osteoblasts and fibroblasts (Bitar et al., 2004). For these reasons, calcium phosphate glasses have great potential in the development of degradable devices, as well as in the building of temporary scaffolds intended to support the regeneration of hard tissues (Hope et al., 2011).

In previous work, polymeric fibers of PLGA and poly (isoprene) supplemented with hydroxyapatite (HA) and $\alpha$-tricalcium phosphate $(\alpha$-TCP) were obtained, and the thermal, mechanical and morphological properties of these fibers were evaluated. It is safe to say that the presence of ceramics in the fibers shows potential in terms of further investigations aimed at bone tissue regeneration (Vechietti et al., 2014). Many articles have reported nanocomposite electrospinning using biodegradable synthetic polymers with bioactive inorganic nanoparticles, such as tricalcium phosphate and bioactive glasses, and most of these nanocomposite nanofibers demonstrated some improvement in the mechanical properties and/or bone cell functions (Deng, et al. 2007; Han et al., 2012).

Electrospinning of composite solutions, however, is not easily implemented. The formation of nanofibers combined with structure inorganics, the size of the particles, their homogeneity/dispersion, and the added amount have remained barriers to improving the success of electrospinning. In many cases, fibers form discontinuous beads, destroying continuous fibrous morphology; this is mainly due to the involvement of inorganic crystals (Jose et al., 2009).

Therefore, one of the biggest considerations in the composite electrospinning process is how to prepare fine nanocrystalline particles and then disperse them ho- mogeneously within the polymer solution. It is common to chemically modify the surface of bioglasses using a silanization pretreatment that can improve glass incorporation in the polymeric matrix, in order to reinforce the adhesion between the inorganic filler and the matrix polymer (Zhang et al., 2008).

The aim of this paper is to establish the optimal experimental conditions for obtaining fibrous structures by electrospinning from a polymeric solution of PLGA with the addition of calcium phosphate glasses $(\mathrm{CaO}$ $\mathrm{P}_{2} \mathrm{O}_{5}-\mathrm{Na}_{2} \mathrm{O}$ ) that have been chemically modified by anchoring a silane coupling agent to the surface. When combined with PLGA, calcium phosphate glasses allow the development of biodegradable composites with load-bearing requirements.

\section{METHODS}

\section{A. Materials and preparation of polymer solutions}

The polymer solution was prepared by dissolving PGLA (ratio 85:15, PURASORB ${ }^{\circledR}$, Holland) in a $3: 1$ mixture of dimethyl sulfoxide (DMSO, Sigma Aldrich, Brazil) and dichloromethane (DCM, LabSynth, Brazil) at a concentration of $4 \mathrm{wt} \%$. Solutions were agitated at room temperature on a roller for at least $24 \mathrm{~h}$, to allow complete polymer dissolution. To prepare the composite, bioactive glass was used with a nominal composition (mol \%) of $44.5 \mathrm{CaO}-44.5 \mathrm{P}_{2} \mathrm{O}_{5}-11 \mathrm{Na}_{2} \mathrm{O}$ (BV) synthesized by the authors at the University of Barcelona, previously silanized with $\gamma$-methacryloxypropyltrimethoxysilane ( $\gamma$-MPS) (Morejón et al., 2014). This was then added to the polymeric solution at concentration of $1 \%$ wt.\%. Each solution was homogenized using a vibracell ultrasonicator (40 kHz, UltraCleaner 800, Brazil) prior to electrospinning.

\section{B. Electrospinning}

The polymer solution was transferred to a $10 \mathrm{~mL}$ syringe and positioned in the pump for the electrospinning process. The solution was pushed towards the electrospinning nozzle at a rate of $5 \mathrm{~mL} / \mathrm{h}$. The experiments were conducted using capillaries $0.7 \mathrm{~mm}$ in diameter with a drum collector rotation speed of $300 \mathrm{rpm}$ in the first series of experiments and between 600 and 800 $\mathrm{rpm}$ in the second. The distance between the needle tip and the ground electrode was $8 \mathrm{~cm}$. A positive voltage was applied to the polymeric solutions of between 9 and $15 \mathrm{kV}$. The electrospinning process was conducted at $15-16^{\circ} \mathrm{C}$.

\section{Gel permeation chromatography (GPC)}

The separation was performed using Viscotek TDAmax equipment via manual injection columns. The volume of the injections was $150 \mu \mathrm{L}$. Four columns in series and a refractive index detector (Waters 410) were used. Tetrahydrofuran (THF, Sigma Aldrich, Brazil) was used as the mobile phase with a flow of $1 \mathrm{~mL} / \mathrm{min}$ and as a solvent for solubilizing the sample. The standard used for the construction of calibration curves was standard polystyrene.

\section{Scanning electron microscopy (SEM)}

Samples of PLGA and PLGA+BV composites were mounted on an aluminum tub using a carbon tape adhe- 
sive. The materials were coated with gold for $30 \mathrm{sec}-$ onds using a Cressington 208HR sputter coater (Vortex Control Systems Inc., Texas, USA). High resolution images of the samples were taken using a JEOL 6060 scanning electron microscope (JEOL, Tokyo, Japan). For each sample, three different areas were observed randomly at different magnifications. The diameters of the resulting fibers were analyzed using Image $\mathrm{J}$ software. The diameters of at least 50 fibers were measured for each sample, and the average fiber diameter was expressed as the mean \pm SD. Statistical analyses of the fiber diameters were conducted using a student's t-test. A value of $p<0.05$ was considered to be statistically significant and $p<0.01$ highly significant.

E. Fourier transform infrared spectroscopy (FTIR)

The surface chemistry of the samples was analyzed using an FTIR spectrometer (Perkin Elemer model Spectrum 1000 FTIR, Germany). Each spectrum of the pure PLGA fibers, BV powders, and PLGA+BV composite were measured in the range 400 to $4000 \mathrm{~cm}^{-1}$ at room temperature $\left(25^{\circ} \mathrm{C}\right)$.

\section{F. Acellular bioactivity test}

An assessment of in vitro bioactivity was carried out by soaking samples in Simulated Body Fluid (SBF), prepared using the method proposed by Kokubo and Takadama (2006). SBF solution has a composition and concentration similar to the inorganic parts of human plasma. The PLGA fibers, with and without BV, were cut into rectangular pieces of $10 \times 10 \mathrm{~mm}$ and then incubated in $10 \mathrm{~mL}$ of SBF at $37^{\circ} \mathrm{C}$ for up to 15 days. The fluid was changed every two days. After 7 and 15 days, fibers were removed and dried in air at room temperature for further characterization. Affiliated energydispersive X-ray spectroscopy (EDS) was used to analyze the elements of the formation of an apatite-like layer on the surface of the samples.

\section{A. Chemical Characterization}

The characteristics of the polymer were obtained using gel chromatography method (GPC); the results of this analysis are presented in Table 1.

The molecular weight of the polymer is another important parameter of the solution that affects the morphology of the electrospun fiber (Haghi and Akbari, 2007). The PLGA used in this work had a molecular weight of approximately $220,000 \mathrm{~g} / \mathrm{mol}$; in general, polymer solutions with high molecular weight provide the desired viscosity for fiber generation. It has been observed that a solution with too low a molecular weight tends to form beads rather than fibers, and a high molecular weight gives fibers with larger average diameters. These average values reflects the number of entanglements of the polymer chains in a solution, and thus the viscosity of the solution. Chain entanglement plays an important role in the processing of electrospinning. Hence, even when the polymer concentration in the solution is low, enough entanglements of the polymer chains can be maintained to ensure a sufficient level of solution viscosity in order to produce a uniform jet dur-
Table 1 Characteristics of PGLA

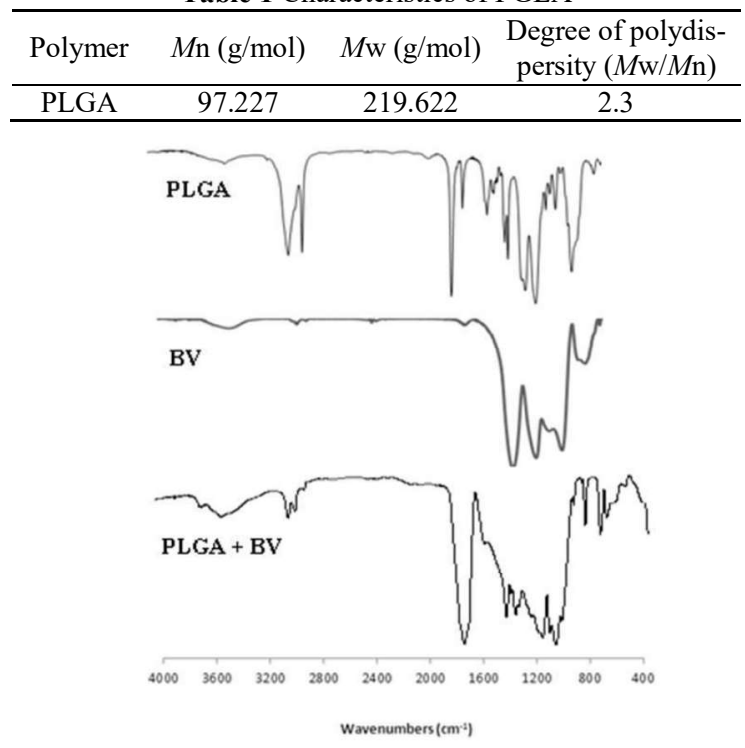

Figure 1. FTIR spectra of PLGA, BV and PLGA+BV.

ing electrospinning and to restrain the effects of surface tension, which plays a significant role in bead formation in electrospun fibers (Gupta et al., 2005).

The FTIR spectra obtained from pure PLGA, BV and PLGA+BV fibers are shown in Fig. 1. The spectra obtained from pure PLGA fibers and from BV powder serve as controls. It can be seen that for pure PLGA films, the strong characteristic adsorption peaks at about $3010 \mathrm{~cm}^{-1}$ correspond to the $-\mathrm{CH}(\mathrm{CH} 3)$ - groups, those at $1752 \mathrm{~cm}^{-1}$ correspond to the $\mathrm{C}=\mathrm{O}$, and those at 1452 $\mathrm{cm}^{-1}, 1182 \mathrm{~cm}^{-1}$ and $1130 \mathrm{~cm}^{-1}$ correspond to the carbonyl $\mathrm{C}-\mathrm{O}$ bond, the $\mathrm{C}-\mathrm{O}-\mathrm{C}$ ether group and the $\mathrm{C}-\mathrm{H}$ methyl group, respectively. The spectrum for silanized glass powder reveals the characteristic peak assigned to $\mathrm{PO}^{-3}$, the band at $\sim 1300-1250 \mathrm{~cm}^{-1}$ is assigned to asymmetric stretching modes, $v_{a s}(\mathrm{O}-\mathrm{P}-\mathrm{O})$, and the band at $1147 \mathrm{~cm}^{-1}$ corresponds to $v_{\mathrm{s}}(\mathrm{O}-\mathrm{P}-\mathrm{O})$ (Rajendran et al., 2007). The vibrations at $2945 \mathrm{~cm}^{-1}$ correspond to the $v_{\text {as }}\left(-\mathrm{CH}_{3}\right)$ and $v_{\mathrm{s}}\left(-\mathrm{CH}_{2}\right)$ respectively of the carbonated chain of the $(\gamma$-MPS) (Morejón et al., 2014). The spectrum of the PLGA+BV sample displays characteristics from both PLGA and BV. Only very small differences were seen in the characteristic PLGA peaks $(\mathrm{C}=\mathrm{O}$ band $)$.

\section{B. Morphological Characterization}

It is well known that fiber diameter is strongly influenced by polymeric concentration; this was therefore kept constant (4 wt.\%) in all experiments (Haghi and Akbari, 2007; Bhardwaj and Kundu, 2010). The experimental conditions for electrospinning were optimized to avoid typical problems such as bead formation and to obtain a uniform diameter distribution. The selection of the spinning voltage was essential to ensure a stable, conical liquid jet which minimized bead formation (Yordem et al., 2008).

In the first series of measurements, a 4 wt.\% PLGA solution in a 3:1 mixture of DMSO and DCM as related to the polymer mass was used. Electrospinning was 

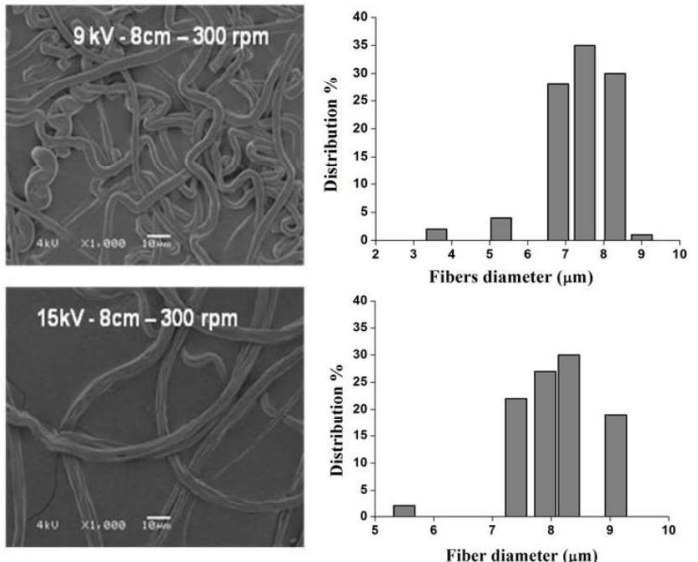

Figure 2. SEM images and distribution of diameters of electrospun fibers at $300 \mathrm{rpm}$.
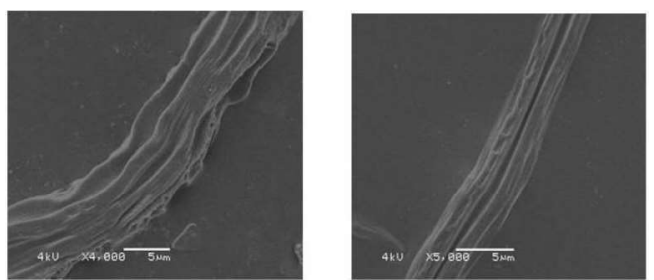

Figure 3. Morphology of damage to PLGA fibers at $15 \mathrm{kV}$.

conducted with applied voltages of 9 and $15 \mathrm{kV}$, respectively, and the rotation speed of the drum collector was $300 \mathrm{rpm}$. The experiments were conducted at $15-16^{\circ} \mathrm{C}$ due to the high volatility of the both solvents, and since a higher temperature caused polymer curing while it was still on the needle. To calculate the transverse dimension values, approximately 50 fibers were analyzed for each alternative. Figure 2 shows the morphology of the electrospun fiber characterized by SEM.

Under the experimental conditions employed, the results of the first experimental series indicated that there was a wide dispersion in the morphology of the fibers obtained, and the prevailing fiber pattern had no orientation. The rotating collector was useful in obtaining dry fibers; it also provided more time to evaporate the solvents and improved the fiber morphology (Ishii et al., 2008).

The obtained fibers were classified as microfibers, since their transverse dimensions exceeded $1 \mu \mathrm{m}$ in each case. At high level of voltage $(15 \mathrm{kV})$, superficial damage to the fibers was detected (Fig. 3) (Zheng et al. 2012). Currently, there is little dispute about the behavior of applied voltage in the electrospinning process (Salazar et al., 2014). Researchers have shown that when higher voltages are applied, there is more polymer ejection, and this facilitates the formation of a fiber with a larger diameter (Thompson et al., 2007; Zhang and Chang, 2007). Other authors have reported that an increase in the applied voltage (i.e., by increasing the electric field strength), increases the electrostatic repulsive force on the fluid jet, which ultimately favors the narrowing of the fiber diameter and may create defects. In our case, it is likely that a higher voltage increases the Coulomb forces in the jet as well as a giving strong-
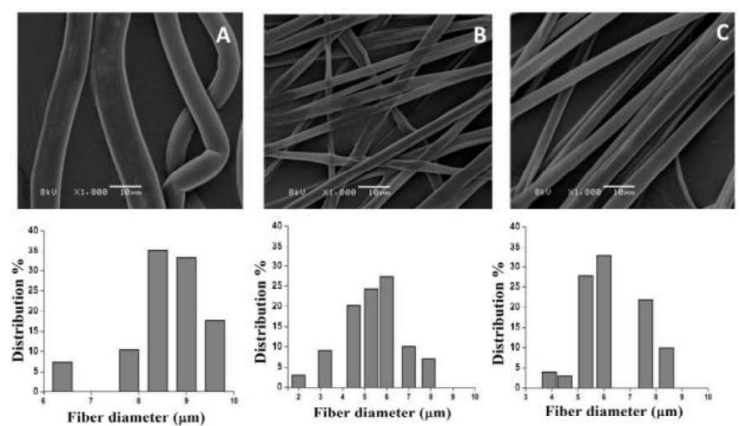

Figure 4. SEM images and distribution of fiber diameters of electrospun fibers at A) $600 \mathrm{rpm}-8 \mathrm{~cm}-9 \mathrm{kV}$, B) $700 \mathrm{rmp}-8 \mathrm{~cm}-$ $9 \mathrm{kV}$ and C) $800 \mathrm{rpm}-8 \mathrm{~cm}-9 \mathrm{kV}$.

er electric field, and these effects lead to damage to the fiber diameter. In addition, the fast evaporation of the solvent produced by high levels of applied voltage could cause the incomplete production of fibers (Haghi and Akbari, 2007; Yordem et al., 2008; Veleirinho et al., 2008).

There are a variety of parameters that influence the morphology and diameter of the electrospun fibers; in particular, the morphology and structure of the deposited fibers are strongly dependent on the collection method. The fiber alignment is determined by the type of collector and its rotation speed. Several research groups have demonstrated the use of a rotating drum for obtaining electrospun fibers that are aligned more or less parallel to each other (Suna et al., 2013; Zhang et al., 2008). Thus, it was decided to increase the speed of collector drum to achieve aligned fibers with a smaller diameter.

The second cycle of experiments was intended to determine the optimal drum collector rotation speed. Values of 600,700 and $800 \mathrm{rpm}$ were tested at a constant voltage $(9 \mathrm{kV})$ (Fig. 4). As the speed increases, the fibers show a higher degree of settling, exhibiting a more aligned and parallel pattern. When the electrospun fiber is aligned, it is thought to guide tissue cells in the direction of the fiber, and this is particularly relevant in the case of aligned tissues such as nerves and muscles (Kim et al., 2010). The smallest transverse dimension of the fibers was obtained for speeds of 700 and $800 \mathrm{rpm}$. The sizes of the fibers obtained under these new conditions were around 3-8 $\mu \mathrm{m}$.

The second stage of the experiments was completed at this point, under the following conditions: a distance between the electrodes of $8 \mathrm{~cm}$, a difference of potentials between electrodes of $9 \mathrm{kV}$, a needle diameter of $0.7 \mathrm{~mm}$ and a rotation speed of the drum collector of $800 \mathrm{rpm}$. It can be seen that two factors directly determine the pattern of the fiber: the drum collector speed and the voltage applied to the system.

The subsequent phase of the study was concerned with establishing the conditions of fiber formation from PLGA solution with $1 \mathrm{wt} . \%$ of bioactive glass base on $\mathrm{CaO}-\mathrm{P}_{2} \mathrm{O}_{5}-\mathrm{Na}_{2} \mathrm{O}$ previously silanized with $\gamma$-MPS (Fig. 4). The experimental conditions and procedure were the same as in the previous case. 

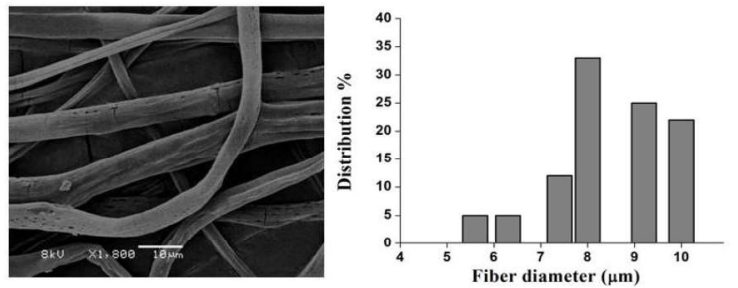

Figure 5. SEM images and distribution of fiber diameters of electrospun fibers with $1 \% \mathrm{BV}$ as related to the polymer mass.
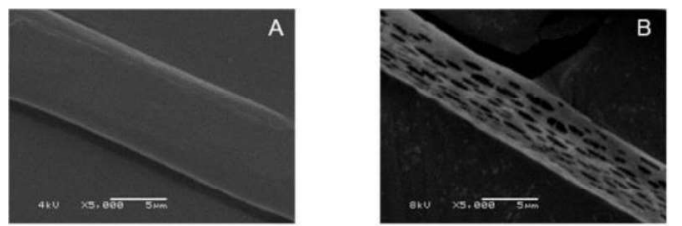

Figure 6. SEM micrographs: A) PLGA fiber and B) PLGA+BV fiber.

Calcium phosphate glass, $\mathrm{CaO}-\mathrm{P}_{2} \mathrm{O}_{5}-\mathrm{Na}_{2} \mathrm{O}$, is a material which has good potential for developing biodegradable materials for medical applications due to its solubility. The interest in this type of glass is because of its similarity to the chemical composition of natural bone; good biocompatibility and low toxicity are therefore expected. The solubility of $\mathrm{CaO}-\mathrm{P}_{2} \mathrm{O}_{5}-\mathrm{Na}_{2} \mathrm{O}$ can be adjusted according to the specific application by modifying its composition.

The results of this study indicate that the quality of the obtained fibers was considerably lower than the fibers formed without BV fillers (Fig. 5). Beachley and Wen (2009) showed that the addition of substances changes the viscosity of the solution, which can cause the formation of discontinuous fibers with holes. However, the average transverse dimension did not differ significantly from that of the fibers spun from pure PLGA polymer.

Micrographs with 5000x magnification of the electrospun samples revealed that pure PLGA fibers had a smooth surface (Fig. 6A), whereas small cracks were visible in some fibers with 1 wt.\% BV (Fig. 6B). This change in the morphology of the fiber surface may play an important role in supporting cell attachment (Nam et al., 2007; Shabani et al., 2012).

Fiber porosity is another controllable parameter that has been extensively studied, in particular for tissue engineering and filtration applications. There are many approaches to controlling the pore size in fiber; one possibility is the addition of salt particles or crystals to the electrospinning solution (Zhu et al., 2008). The presence of pores in the fibers containing inorganic particles causes an increase in the rate of the phase separation of the polymer from the solvent during the electrospinning process (Yang et al., 2006). Kim et al., (2008) demonstrated that the specific surface area of the fibers increases substantially upon addition of inorganic particles, and that the surface properties are also modified. The incorporation of a $\mathrm{CaP}$ phase in the polymeric matrix also enhances the mechanical properties of the material and favors an ionic environment, modulating cell behavior.

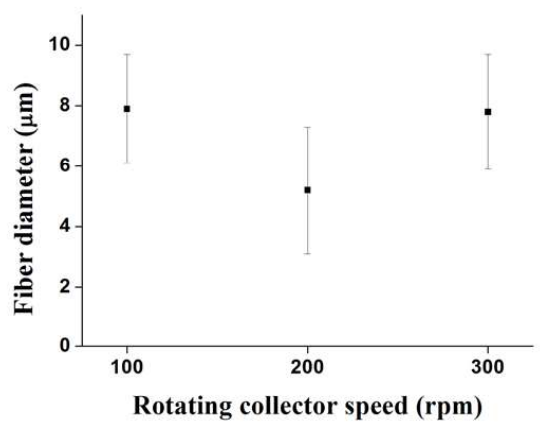

Figure 7. Influence of the rotating collector speed on the fiber diameters obtained for a 4 wt.\% PLGA solution with and without 1 wt.\% BV (experimental conditions: distance $8 \mathrm{~cm}$, needle diameter $0.7 \mathrm{~mm}$, flow rate $5 \mathrm{~mL} / \mathrm{h}$ and voltage $9 \mathrm{kV}$ ).

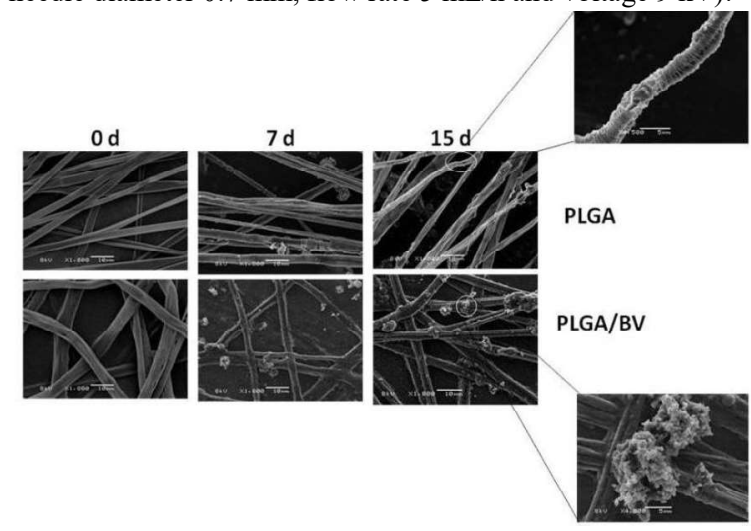

Figure 8. SEM images of control PLGA and PLGA+BV fibers mineralized in SBF at $37^{\circ} \mathrm{C}$ for 0,7 and 15 days, respectively.

Figure 7 shows that the average fiber diameter obtained at $300 \mathrm{rpm}(7.9 \pm 1.8 \mu \mathrm{m})$ was statistically higher than that of fibers obtained at $800 \mathrm{rpm}(5.2 \pm 2.1 \mu \mathrm{m})$ $(p<0.05)$, indicating that an increase of $500 \mathrm{rpm}$ in rotation speed is effective in reducing the diameter of PLGA fibers. Compared with PLGA fibers at $800 \mathrm{rpm}$, the average fiber diameter of PLGA+BV was higher $(7.8 \pm 1.9 \mu \mathrm{m})(p<0.05)$, suggesting that the inclusion of inorganic particles results in an increase in the fiber diameter. Under the experimental conditions used, none of the diameters obtained showed highly significant statistical differences $(p<0.01)$.

\section{Acellular bioactivity test}

The bone-bonding potential of a biomaterial is often estimated by examining its ability to form a layer of hydroxycarbonate apatite on its surface when exposed to SBF (Gönen et al., 2016). In order to confirm the formation of this layer, the composite fibers were analyzed using SEM and EDX.

Visual inspection of the PLGA fiber showed no sign of mineral formation after a two week study (Fig. 8), suggesting that the formation of hydroxyapatite did not occur when immersed in SBF. Higher magnification of an area of PLGA fibers revealed that they were composed of flake crystals. With prolongation of the incubation time, the mineralization was scarcely improved on the PLGA fibers. It is possible that after a longer contact 
time with SBF, apatite minerals will appear. Zhang et al. (2009) observed that positively charged calcium ions in the solution are attracted to the hydrolyzed PLGA surface and that apatite forms through the attraction of phosphate groups from the solution and the increase of local apatite ion activity product.

Some bone-like apatite minerals were observed on the PLGA+BV fibers in comparison with their initial morphology (zero day). The growths obtained after 15 days of assay have the appearance of typical structures of biological apatite (Lao et al., 2011). The existence of calcium phosphate glass particles within the biodegradable polymer fibers has been shown to improve the surface mineralization process. This mineralized surface also plays a direct role in the cellular mineralization process by providing a mineral source for calcification (Jayasuriya et al., 2008; Lao et al., 2001).

The calcium phosphate glass studied with a composition base of $44.5 \mathrm{CaO}-44.5 \mathrm{P}_{2} \mathrm{O}_{5}-11 \mathrm{Na}_{2} \mathrm{O}$ has a high solubility, therefore increasing the interchange of ions with the environment from the initial stages of the immersion in the SBF solution, and thus enhancing the nucleation and precipitation of calcium phosphate compounds (Morejón et al., 2014).

These results indicate that silanized BV has a positive effect on the nucleation and crystallization processes, since the addition of even a small quantity of calcium phosphate glass results in an obvious variation in the surface morphology after soaking in SBF. It is important to remember that the previous process of silanization introduces - $\mathrm{Si}-$ groups onto the $\mathrm{BV}$ surface. These $\mathrm{Si}$ ions have the specific function of promoting the bioactive behavior of glasses and conveniently offer nucleation sites for HA formation.

The chemical compositions of one area of each type of fiber were detected using EDX (Fig. 9). The typical spectra of PLGA were obtained for the fibers immersed in $\mathrm{SBF}$, containing $\mathrm{C}, \mathrm{O}$, and small amounts of $\mathrm{Ca}$, a product of the SBF environment, while those of the PLGA+BV fibers showed $\mathrm{P}, \mathrm{Ca}$ and $\mathrm{Na}$.

Previous research has correlated the bone integration potential with the ability of biomaterials to develop bone-like apatite upon soaking in SBF (Zhang et al., 2008). Some bioactive glasses have been shown to stimulate angiogenesis in vitro and in vivo, and the possible antibacterial and inflammatory effects of bioactive glasses have also been investigated (Vila et al., 2013). For these reasons, calcium phosphate glasses show great potential in the development of degradable devices, as well as in the building of temporary scaffolds intended to support the regeneration of hard tissues.
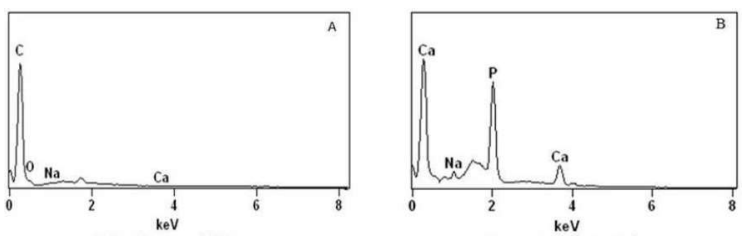

Figure 9. EDX spectra of fibers after immersion in SBF solution for 15 days: (A) PLGA and (B) PLGA+BV.
A similar increase in bone-like minerals was observed by Schneider et al. (2008) and Zhang et al. (2009) when PLGA/amorphous tricalcium phosphate electrospun nanocomposites were immersed in SBF, and electrospun PLGA (75/25)/multi-walled carbon nanotube nanofibers were incubated in SBF solutions for up to 21 days, respectively. This demonstrates that the PLGA fibers alone have little ability to induce bonelike mineral growth, due to a lack of sufficient functional groups, while the incorporated bioactive substances can function as nucleation sites to accelerate mineral growth (Ngiam et al., 2009).

While the composition of SBF was close to that of blood plasma (Jayasuriya et al., 2008), the stronger biomineralization ability of the PLGA/BV fibers may indicate that these have good bioactivity that can induce calcium mineralization for bone regeneration.

\section{CONCLUSIONS}

The preliminary results suggest that electrospun PLGA fibers that are significantly uniform and highly smooth can be obtained under the following conditions: distance between electrodes $8 \mathrm{~cm}$, difference in potentials between electrodes $9 \mathrm{kV}$, needle diameter $0.7 \mathrm{~mm}$, and rotation speed of the drum collector $800 \mathrm{rpm}$. The electrospun fibers have an average diameter of $5 \mu \mathrm{m}$, in the range 3 to $8 \mu \mathrm{m}$. The best morphology of the alignment of the fibers was obtained with an increment in the rotation speed. Lesser quality was found for the PLGA/calcium phosphate glass fibers in comparison with the fibers produced without BV fillers. However, no significant difference was observed in the average transverse dimension in comparison with fibers spun from pure PLGA polymer. An assay using SBF indicated that previously silanized BV with PLGA fibers have a better bioactivity for inducing calcium mineralization. Further detailed studies are ongoing these are required to complete the characterization of the composite fibers for the intended applications.

\section{ACKNOWLEDGMENTS}

The authors acknowledge the Coordenação de Aperfeiçoamento de Pessoal de Nível Superior (CAPES) for financial support through the CAPES-MES/Cuba project No. 163/12.

\section{REFERENCES}

Beachley, V. and X.J. Wen, "Effect of electrospinning parameters on the nanofiber diameter and length," Materials Science and Engineering: C, 29, 663668 (2009).

Bhardwaj, N. and S.C. Kundu, "Electrospinning: A fascinating fiber fabrication technique," Biotechnology Advances, 28, 325-347 (2010).

Bitar, M., V. Salih, V. Mudera, J.C. Knowles and M.P. Lewis, "Soluble phosphate glasses: In vitro studies using human cells of hard and soft tissue origin," Biomaterials, 25, 2283-2292 (2004).

Deng, X.L., G. Sui, M.L Zhao, G.Q. Chen and X.P. Yang, "Poly(L-lactic acid)/hydroxyapatite hybrid nanofibrous scaffolds prepared by electrospin- 
ning," J Biomater Sci Polym Ed., 18, 11-130 (2007).

Formhals, A., Process and apparatus for preparing artificial threads, U.S. Patent, 1975504 (1934).

Gönen, S.O., E. T. Melek and S. Küçükbayrak, "Fabrication of bioactive glass containing nanocomposite fiber mats for bone tissue engineering applications," Composite Structures, 138, 96-106 (2016).

Gupta, P., C. Elkins, T.E. Long and G.L. Wilke, "Electrospinning of linear homopolymers of poly (methylmethacrylate): exploring relationships between fiber formation, viscosity, molecular weight and concentration in a good solvent," Polymer, 46, 4799-4810 (2005).

Haghi, A.K and M. Akbari, "Trends in electrospinning of natural nanofibers," Phys Status Solidi, 204, 1830-1834 (2007).

Han, X.J., Z.M. Huang, C. Huang, Z.F. Du, H. Wang, J. Wang and C.L. He, "Preparation and Characterization of Electrospun Polyurethane/InorganicParticles Nanofibers," Polymer Composites, 33, 2045-2057 (2012).

Hope, A., N.S. Guldal and A.R. Boccaccini, "A review of the biological response to ionic dissolution products from bioactive glasses and glassesceramic," Biomaterials, 32, 2757-2774 (2011).

Ishii, Y., H. Sakai and H.A. Murata, "A new electrospinning method to control the number and a diameter of uniaxially aligned polymer fibers," Mater. Lett., 62, 3370-3372 (2008).

Jayasuriya, A.C., C. Shah, N.A. Ebraheim and A.H. Jayatissa, "Acceleration of biomimetic mineralization to apply in bone regeneration," Biomed $\mathrm{Ma}$ ter., 3, 1-6 (2008).

Jose, M.V., V. Thomas, K.T. Johnson, D.R. Dean and E. Nyairo, "PLGA/HA nanofibrous nanocomposite scaffolds for bone tissue engineering," Acta Biomaterialia, 5, 305-315 (2009).

Kim, T.G., H.J Chung and T.G. Park, "Macroporous and nanofibrous hyaluronic acid/collagen hybrid scaffold fabricated by concurrent electrospinning and deposition/leaching of salt particles," Acta Biomaterialia, 4, 1611-1619 (2008).

Kim, S.J., D.H. Jang, W.H. Park and B. Min, "Fabrication and characterization of 3-dimensional PLGA nanofiber/microfiber composite scaffolds", Polymer, 51, 1320-1327 (2010).

Kokubo, T. and H. Takadama, "How useful is SBF in predicting in vivo bone bioactivity?," Biomaterials, 27, 2907-2915 (2006).

Lannutti, J., D. H. Reneker, D. Tomasko and D. Farson, "Electrospinning for tissue engineering scaffolds," Mater Sci. Eng. C., 27, 504-509 (2007).

Lao, L., Y. Wang, Y. Zhu, Y. Zhang and C. Gao, "Poly(lactide-co-glycolide)/hydroxyapatite nanofibrous scaffolds fabricated by electrospinning for bone tissue engineering," J Mater Sci: Mater Med., 22, 1873-1884 (2011).

Liang, D., B.S. Hsiao and B. Chu, "Functional electrospun nanofibrous scaffolds for biomedical applica- tions," Adv. Drug Deliv. Rev., 59, 1392-1412 (2007).

Lin, H.M., Lin, Y.H. and Hsu, F.Y "Preparation and characterization of mesoporous bioactive glass/polycaprolactone nanofibrous matrix for bone tissues engineering," J. Mater. Sci. Mater. Med., 23, 2619-2630 (2012).

Long, Y.Z., M.M. Li, C.Z. Gu, M.X. Wan, J.L. Duvail and Z.W. Liu, "Recent advances in synthesis, physical properties and applications of conducting polymer nanotubes and nanofibers," Progress in Polymer Science, 36, 1415-1442 (2011).

Morejón, L., J.A. Delgado, M. Tarttagó, J.A. Álvarez, M. García-Vallés, S. Martinez and M. Ginebra, "Calcium phosphate glasses: Silanation process and effect on the bioactivity behavior of glassPMMA composites," Journal of Biomedical Materials Research B: Applied Biomaterials, 102, 205213 (2014).

Nam, J., Y. Huang, S. Agarwal and J. Lannutti, "Improved cellular infiltration in electrospun fiber via engineered porosity," Tissue Engineering, 13, 2249-2257 (2007).

Ngiam, M., S.S. Liao, A.J. Patil, Z.Y. Cheng, C.K. Chan and S. Ramakrishna, "The fabrication of nano-hydroxyapatite on PLGA and PLGA/collagen nanofibrous composite scaffolds and their effects in osteoblastic behavior for bone tissue engineering," Bone, 45, 4-16 (2009).

O'Brien, F. "Biomaterials \& scaffolds for tissue engineering," MaterialsToday, 14, 88-95 (2011).

Rajendran, V., A.V. Gayathri, M. Azooz and F.H. ElBatal, "Physicochemical studies of phosphate based $\mathrm{P}_{2} \mathrm{O}_{5}-\mathrm{Na}_{2} \mathrm{O}-\mathrm{CaO}-\mathrm{TiO}_{2}$ glasses for biomedical applications," Journal of Non-Crystalline Sol$i d s$, 353, 77-84 (2007).

Reneker, D.H. and A.L. Yarin, "Electrospinning jets and polymer nanofibers," Polymer, 49, 2395-2425 (2008).

Salazar, J.R., I.A. Hidalgo and M.A. Sabino, "Estudio del efecto de las variables de proceso en la morfología de andamios 3D obtenidos por la técnica de electrospinning," Rev. LatinAm. Metal. Mat., S6, 23-24 (2014).

Schneider, O.D., S. Loher, T.J. Brunner, L. Uebersax, M. Simonet and R.N Grass, "Cotton wool-like nanocomposite biomaterials prepared by electrospinning: in vitro bioactivity and osteogenic differentiation of human mesenchymal stem cells," $\mathrm{J} \mathrm{Bi}$ omed Mater Res B, 84, 350-362 (2008).

Shabani, I., V. Haddadi-Asl, E. Seyedjafari and M. Soleimani, "Cellular infiltration on nanofibrous scaffolds using a modified electrospinning technique," Biochemical and Biophysical Research Communications, 423, 50-54 (2012).

Suna, B., Y.Z. Long, H.D. Zhang, M.M. Li, J.L. Duvail, X.Y. Jiang and H.L. Yin, "Advances in threedimensional nanofibrous macrostructures via electrospinning," Progress in Polymer Science, 39, 862-890 (2013). 
Thompson, C.J., G.G. Chase, A.L. Yarin and D. Reneker, "Effects of parameters on nanofiber diameter determined from electrospinning model," Polymer, 48, 6913-6922 (2007).

Veleirinho, B., M.F. Rei and J.A. Lopes-da-Silva, "Solvent and concentration effects on the properties of electrospun poly (ethylene terephthalate) nanofiber mats," J Polym Sci B Polym Phys., 46, 460-471 (2008)

Vechietti, F., D. Marques, N.O. Muniz and L.A.L. Santos, "Fibers obtaining and characterization using Poly (Lactic-co-Glycolic Acid) and Poly (Isoprene) containing hydroxyapatite and $\alpha$-TCP calcium phosphate by Electrospinning Method," Key Engineering Materials (Online), 631, 173-178 (2014).

Vila, O.F., J.R. Bago, M. Navarro, M. Alieva, E. E. Aguilar, E. Engel, J. Planell, N. Rubio and J. Blanco, "Calcium phosphate glass improves angiogenesis capacity of poly(lactic acid) scaffolds and stimulates differentiation of adipose tissue derived mesenchymal stromal cells to the endothelial lineage," J Biomed Mater Res Part A, 101A, 932-941 (2013).

Yang, F., W. Cui, Z. Xiong, L. Liu, J. Bei and S. Wang, "Poly(L,L-lactide-co-glycolide)/ tricalcium phosphate composite scaffold and its various changes during degradation in vitro," Polym Degrad Stabil., 91, 3065-3073 (2006).

Yordem, O.S., M. Papila and Y.Z. Menceloğlu, "Effects of electrospinning parameters on polyacrylonitrilenano fiber diameter: an investigation by response surface methodology," Mater Des., 44, 3444 (2008).

Zander, N.E., "Hierarchically Structured Electrospun Fibers," Polymers, 5, 19-44 (2013).

Zhang, D. and D. Chang, "Patterning of Electrospun Fibers Using Electroconductive Templates," J. Adv. Mater., 19, 3664-3667 (2007).

Zhang, Y., J.R. Venugopal, A. El-Turki, S. Ramakrishna, B. Su and C.T. Lim, "Electrospun biomimetic nanocomposite nanofibers of hydroxyapatite/ chitosan for bone tissue engineering," Biomaterials, 29, 4314-4322 (2008).

Zhang, H.L., J.S. Liu, Z.W. Yao, J. Yang, L.Z. Pan and Z.Q. Chen, "Bio- mimetic mineralization of electrospun poly (lactic-co-glycolic acid)/multi-walled carbon nanotubes composite scaffolds in vitro," Mater Letters, 63, 2313-2316 (2009).

Zheng, J., Y.Z Long, B. Sun, Z.H. Zhang, F. Shao and H.D. Zhang, "Polymer nanofibers prepared by lowvoltage near-field electrospinning," Chinese Physics B, 21, 1-6 (2012).

Zhu, X., W. Cui, X. Li and Y. Jin, "Electrospun fibrous mats with high porosity as potential scaffolds for skin tissue engineering," Biomacromolecules, 9, 1795-1801 (2008).

Received: June 19, 2017.

Sent to Subject Editor: June 23, 2017.

Accepted: April 5, 2018.

Recommended by Subject Editor: María Luján Ferreira 